Journal of CORPORATE RESPONSIBILITy AND LEADERSHIP

The Challenges of Contemporary Management IN THE GLOBAL ECONOMY

\title{
From Editors
}

Dear Readers,

We are proud to present you the next issue of the Journal of Corporate Responsibility and Leadership (JCR\&L). This issue focuses attention on the challenges of contemporary management in the global economy.

Anna Dębczyńska studies differences between Polish and Chinese cultures and makes an attempt to develop practical recommendations for Polish business people to assist them in establishing and cultivating relationships with Chinese partners. She combines theoretical knowledge of the models describing cultural dimensions with the practical understanding of the context and direct experience from the field. The empirical part of the paper is based on the findings from the qualitative study collecting data through structured interviews and the author's individual, participatory observation.

Robert Gawłowski and Paweł Modrzyński explore the development of shared services centres (SSCs) in the private and public sectors in the United Kingdom. Their research is focused on implementing SSCs into the operations of local government administration. Embedded in the context of the new public management, the study points out lessons identified and models of SSCs in public organisations.

Grzegorz Hoppe discusses the ideas of Thomas Piketty manifested in his seminal work Capital in the $21^{\text {st }}$ century and argues with Piketty's proposals of tax changes aimed at levelling the existing income disparities. Hoppe claims that that “implementation of Piketty's fiscal innovations would reduce capital disparities neither among the citizens of a given state nor in the international context" and considers 
income disparities as "the forces driving progress and encouraging entrepreneurship".

Valentyna Ksendzuk and Olena Syvak analyse the challenges for companies operating in Poland and Ukraine associated with currency risks in foreign trade. First of all, they outline the situation of foreign trade in the countries under the study. Secondly, they identify and discuss the types of currency risks. Thirdly, they compare and contrast non-financial reporting of Ukrainian and Polish companies in regard to presenting information about currency risks and applied risk management techniques. Finally, they conclude with recommendations for Ukrainian enterprises to learn lessons in the field of currency risk management from their Polish counterparts.

Arkadiusz Malkowski discusses the issue of developing competitiveness of border regions of the European Union. He theorizes on development of border areas and ambidextrous approaches to cope with the challenges of globalisation and regionalisation through the processes of glocalisation. Then, he analyzes the role of human capital for strengthening the competitiveness of border regions. Malkowski illustrates his discussion with the case study of eastern voivodeships of Poland. He compares and contrasts GDP per capita in this area with other regions as well as anticipated changes in their population and the structure of EU funds absorption.

In addition to research papers, there are included the reports by Barbara Czerniachowicz and Anna Wieczorek-Szymańska on the $8^{\text {th }}$ International Scientific Conference Economy, Management and Environment and the $2^{\text {nd }}$ Szczecin International Spring Management Workshops, which were organised by the Faculty of Economics and Management, the University of Szczecin in May 2017.

We hope that our Readers will find this issue of the Journal of Corporate Responsibility and Leadership an interesting and valuable source of knowledge and expertise. 